\title{
Prescribing Pattern of Antibiotics in Paediatric Patients
}

\author{
B. Ramya Kuber*, D. Avanthi, CH. Sri Lalitha Vaishnavi, S. Jigisha Varma
}

Institute of Pharmaceutical Technology, Sri Padmavati Mahila Visvavidyalayam (Women's University), Tirupati-517502, Andhra Pradesh, INDIA.

\begin{abstract}
Aim: To collect prescriptions from patients, to assess the prescribing pattern in accordance with the available guidelines. Objective: The main objective is to study the Prescribing pattern of antibiotics in hospital paediatric patients. Method: Non- interventional, prospective observational study of Six month's duration was undertaken during August - February of 2016-2017. A total number of 300 prescriptions were screened and 140 patients were enrolled for antibiotic study. Patient data relevant to the study was obtained from the prescriptions in direct interview with out- patients under antibiotic therapy and Children under the age of 7 . Results: A total of 300 paediatric patients fulfilled the inclusion criteria were enrolled. According to our study there were a total of 110 boys (36.6\%) and 190 girls (63.4\%). Among 300 patients, the highest number of patients was in the age group less than one year i.e.32\% and lowest number was in the age group of 3-5 years i.e.19.3\%. In our study, Macrolide antibiotics were found to be widely prescribed. Among all these Macrolide antibioticsAzithromycin (26.2\%) was the leading antibiotic prescribed followed by Cephalosporin's- Cefixime (24.3\%) and the other antibiotics. Most of the antibiotics were administered parenterally for outpatients. Conclusion: Antibiotic prescribing in children is relatively high in Chittoor district of Andhra Pradesh. Prescription of broad-spectrum antibiotics though has increased demonstrably which may result in development of bacterial resistance, however development of guidelines for antibiotic prescription and use of appropriate drugs can result in minimizing the unfavourable use of antibiotics in children.
\end{abstract}

Key words: Antibiotics, Paediatrics, Guidelines, Resistance, Prevalence.

\section{INTRODUCTION}

Paediatrics is the branch of medicine that deals with the medical care of infants, children and adolescents. A medical practitioner whose specializes in this area is known as paediatrician. The word paediatrics and its cognates mean healer of children, they derive from two Greek words: pais = children and iatros $=$ doctor or healer. Paediatrics is concerned with the health of infants, children and adolescents, their growth and development, and their opportunity to achieve full potential as adults. As a physician who assumes a responsibility for children's physical, mental and emotional progress from conception to maturity. ${ }^{1}$ As per ICH guidelines 2000, paediatrics is defined as those younger than 18 years. New-born infants born before 37 weeks of gestation period was termed as premature; those between 1 day to 1 month of age are neonates; 1 month to one year are infants; 1 to 11 years are children and 12 to 16 years are adolescents. ${ }^{2}$ Children are not just the little adults and lack of data on important pharmacokinetic and pharmacodynamics differences had led to several disastrous situations in paediatrics. Prescribing practices are a reflection of health professional's abilities to determinate among the various choices of drugs and determine the ones that will most benefit the patients. The study of prescribing pattern is a part of the medical audit and seeks to monitor, evaluate and if necessary, suggest modification in prescribing practices to make medical care rational and cost effective. Medicine use is rational (appropriate, proper, correct) when patients receive the appropriate medicines, in doses that meet their own individual requirements, for an adequate period of time,
DOI: 10.5530/ijopp.11.3.32

Address for correspondence: Dr. B. Ramya Kuber, M. Pharm, Ph.D., Associate Professor, Institute of Pharmaceutical Technology, Sri Padmavati Mahila Visvavidyalayam (Women's University), Tirupati-517502, Andhra Pradesh, INDIA. Phone no: +919849939565 Email Id: rkuberpharma@yahoo. com

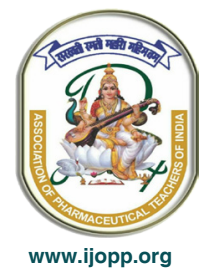


and at the lowest cost both to them and the community. Appropriate drug utilization is in terms of efficacy, safety, convenience and economic aspects at all levels in the chain of drug use. ${ }^{3}$

\section{Rules of prescribing for Paediatric populations}

Antibiotic guidelines are standard set of guidelines for the treatment of infectious diseases based on local culture sensitivity data. These guidelines help the physician to prescribe the antibiotics rationally to paediatric patients when indicated. Judicious use of antibiotic is therefore an important way to reduce the problem of antimicrobial resistance. So, detailed rationale knowledge of antibiotic prescribing pattern must be implemented in the clinical practice.

Antibiotics are the key drugs for treatment of infections and are among the most commonly prescribed drugs in Paediatrics department. Worldwide population constitute of about $28 \%$ of children and infants who are most susceptible to diseases due to under development of immune system. Paediatric groups are among the most vulnerable population groups to contact illnesses and cause harmful effects of drugs due to differences in pharmacodynamics and pharmacokinetics. The use of antimicrobial agents, especially antibiotics has become a routine practice for the treatment of paediatric illnesses. ${ }^{4}$

- Calculate the doses for prescribed drugs based on weight of the patients.

- Ensure proper instructions to the caregiver, including when the child vomits the given medication after consumption.

- Ensure that all medicines are strictly out of reach of children at all times.

- Avoid prolonged treatment with drugs that have delayed complications (Steroids).

- Use antibiotics sparingly and only when required. ${ }^{5}$

\section{Adverse Drug Effects}

Adverse Drug Events (ADEs) describe any untoward medical occurrence that may present during treatment with a pharmaceutical product but that does not necessarily have a causal relationship with this treatment. Adverse Drug Reactions (ADRs) form a part of ADEs. ADRs are defined as an unintended noxious response to a drug. ${ }^{6}$ Adverse drug reactions in children are an important public health problem. We have undertaken a systematic review of observational studies in children in three settings: causing admission to hospital, occurring during hospital stay and occurring in the community. We were particularly interested in understanding how ADRs might be better detected, assessed and avoided. ${ }^{7-8}$
Age in years

$<1$

$1-3$

$4-6$
Common ADR Reported

Rashes and urticaria, anaphylactic shock, fever, vomiting, chills and rigors, acute dystonia, Stevens Johnson syndrome.

Fever, bradycardia, anaphylactic shock, rashes and urticara, aphthous ulcer, diarrhea.

Vomiting, burning sensation, rashes and urticaria, chills and rigors, death

\section{Dosages}

- Children are not mini-adults. Pediatric doses should be obtained from a pediatric dosage reference text and not extrapolated from the adult dose.

- When considering drug use in children, the following age groups should be used: Preterm (born before 37 weeks), neonate (birth to 1 month), infant (1 month to 12 months), child (1 to 12 years) and adolescent (12 to 18 years).

- Unless the age is specified, the term 'child' in the British National Formulary (BNF) includes persons aged 12 years and younger.

\section{AIM}

To study the prescribing pattern of antibiotics in Paediatrics.

\section{OBJECTIVES}

1. To collect prescriptions from patients.

2. To assess the prescribing pattern in accordance with the available guidelines.

\section{MATERIALS AND METHODS}

Study design - Non- interventional, prospective observational study.

Study site - Satya children care clinic located at Muthyal Reddy Palli, Tirupati, Chittoor District, Andhra Pradesh headed by Dr. G. Satyanarayana MBBS, DCH.

Study duration - Study was conducted for 6 months i.e. August to February 2016-2017.

Study population - Total of 300 prescriptions were screened and 140 patients were enrolled for antibiotic study.

Study data - Patient data relevant to the study was obtained from the prescriptions in direct interview. 


\section{Inclusion category}

1. Out- patients under antibiotic therapy.

2. Children under the age of 7 .

\section{Exclusion category}

1. Patient with non-infective diseases.

2. Patient aged above 7 .

\section{ANALYSIS OF DATA}

\section{Statistical analysis}

The data were analysed by using suitable statistical method. Necessary statistical figures were shown using bar diagram, chart and other necessary tools. The data was entered and analysed by using Graph pad prism, version 7.

\section{RESULTS}

A total of 300 paediatric patients fulfilled the inclusion criteria were enrolled. According to our study there were a total of 110 boys (36.6\%) and 190 girls (63.4\%) and gender distribution is shown in the Figure 1.

\section{Age Distribution}

Among 300 patients, the highest number of patients was in the age group less than one year i.e. $32 \%$ and lowest number was in age group 3-5 years i.e.19.3\% - it was shown in Table 1 and Graph 1.

\section{Antibiotics Prescribed}

In our study, Macrolide antibiotics were found to be widely prescribed antibiotic. Among all these Macrolide antibiotics- Azithromycin (26.2\%) was the leading antibiotic prescribed followed by Cephalosporin's-

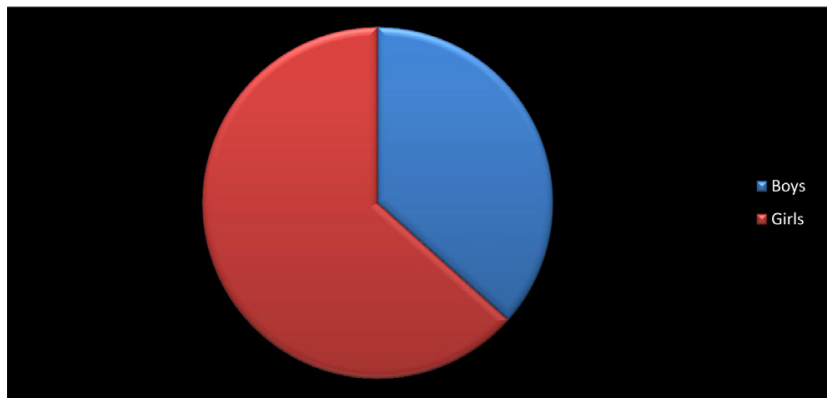

Figure 1: Gender wise Distribution.

\begin{tabular}{ccc}
\multicolumn{3}{c}{ Table 1: Age wise Distribution. } \\
\hline AGE(years) & NO. OF PATIENTS & PERCENTAGE \\
\hline$<1$ & 96 & $32 \%$ \\
$>1-3$ & 64 & $21.3 \%$ \\
$>3-5$ & 58 & $19.3 \%$ \\
$>5-7$ & 84 & $28 \%$ \\
\hline
\end{tabular}

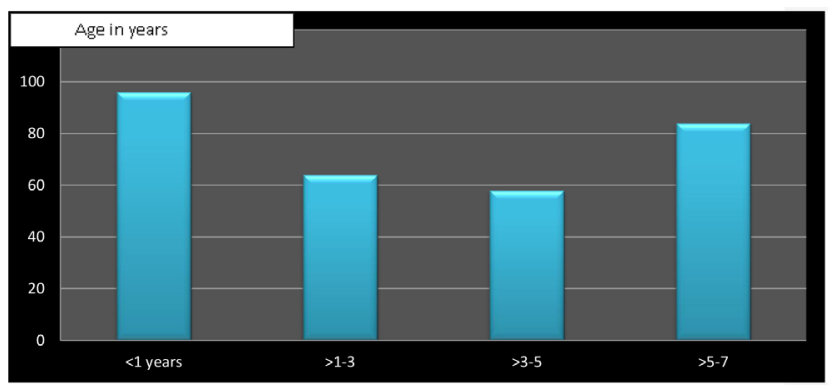

Graph 1: Age wise Distribution.

\begin{tabular}{ccc}
\hline \multicolumn{3}{c}{ Table 2: Distribution of Antibiotics Prescribed. } \\
\hline Antibiotics & No. of patients & Percentage \\
\hline Cefixime & 40 & $24.3 \%$ \\
Azithromycin & 42 & $26.2 \%$ \\
Cefpodoxime & 32 & $20 \%$ \\
Ampicillin & 3 & $1.8 \%$ \\
Ofloxacin & 10 & $6.2 \%$ \\
Chloramphenicol & 2 & $1.2 \%$ \\
Potassium & 10 & $6.2 \%$ \\
clavulanate & & \\
\hline
\end{tabular}

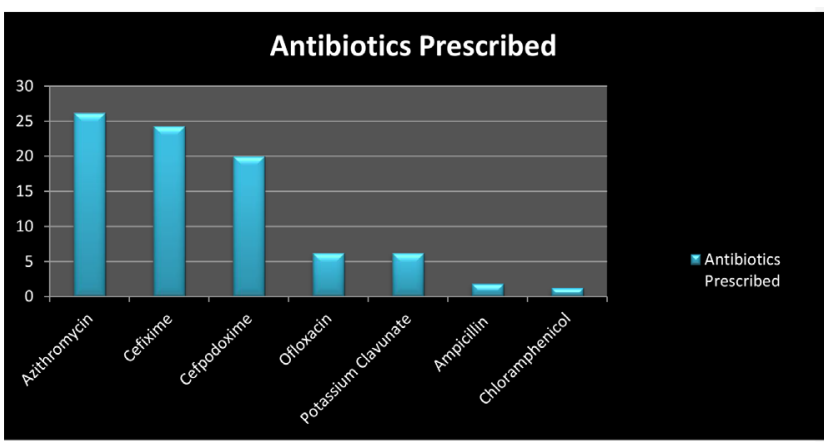

Graph 2: Distribution of Antibiotics Prescribed.

Cefixime $(24.3 \%)$ and the other antibiotics was shown in Table 2 and Graph 2.

\section{Category Wise Prescription of Antibiotics}

In this the antibiotics prescribed were categorized according to their class. Among these the mostly prescribed antibiotics were shown in Table 3 and Graph 3.

\section{DISCUSSION}

Antibiotics represent one of the most commonly used drugs. The prescribing prevalence of antibiotics was also high. The majority of common childhood illnesses are caused by viruses which do not require antibiotics. So, excessive and inappropriate use leads to a number of consequences in term of cost, drug interactions, hospital stay and bacterial resistance. The number of female patients exceeded the male patients. In our study the most commonly prescribed antibiotics in all age Indian Journal of Pharmacy Practice, Vol 11, Issue 3, Jul-Sep, 2018 


\section{Table 3: Class of Antibiotics Prescribed.}

\begin{tabular}{ccc} 
Antibiotics & No. of patients & Percentage \\
\hline Cephalosporins & 72 & $44.3 \%$ \\
Penicillins & 13 & $8 \%$ \\
Tetracyclins & 2 & $1.2 \%$ \\
Fluoroquinolones & 10 & $6.2 \%$ \\
Macrolide antibiotics & 42 & $26.2 \%$ \\
\hline
\end{tabular}

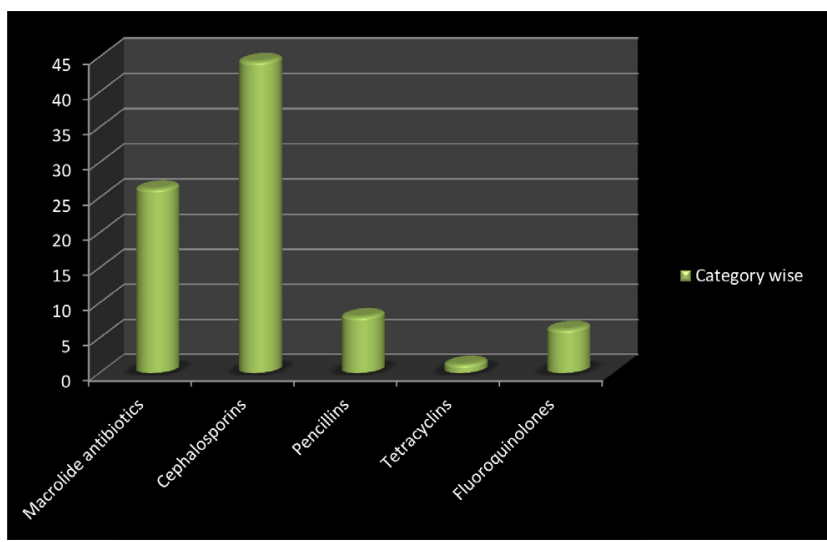

Graph 3: Category Wise Prescription of Antibiotics.

groups were Macrolide, cephalosporins and Penicillins. The difference in the trend of prescribing practice may be due to the difference in the prevalence of disease and availability of the drugs. Higher numbers of antibiotics were prescribed for children whose age was between one and seven years. Tetracyclines were least prescribed because they have serious side effects like complexing with the milk teeth, making the bone fragile and brittle. So they are prescribed only if no other medication are not suitable. Due to allergic reactions of Penicillins in some patients, they were replaced by Macrolide antibiotics like Azithromycin and cephalosporins like Cefixime and Cefpodoxime.

\section{CONCLUSION}

In our study $46.6 \%$ of paediatric patients had received the antibiotic prescriptions. This study gives an overview of the pattern of antibiotic prescription according to the available guidelines. Paediatrics whose age was between one and seven years were given the highest percentage of antibiotics than other age groups. Macrolide antibiotics like Azithromycin were highly prescribed and Tetracyclines like Chloramphenicol were least prescribed among paediatrics. This may be considered as an effort to improve the quality of health care.

\section{CONFLICTS OF INTEREST}

The authors declare no conflict of interest.

\section{ABBREVIATIONS}

ICH: International Conference on Harmonisation; ADE: Adverse Drug Event; ADR: Adverse Drug Reaction.

\section{REFERENCES}

1. Nancy T. Hatfield and broadribb. Introductory pediatric nursing. 2007;28-30.

2. Joseph D, Robert T, Gary Y, Gary M. Pharmacotherapy, A pathophysiologic approach. 2011;15-16.

3. Thapaliya K, Shrestha S, Bhattarai S, Basnet D, Chaudhary RK. Prescribing pattern of antibiotic in pediatric hospital in Chitwan district in Nepal. World J Phar Pharm Sci. 2015;4(11):1631-41.

4. Choudhury DK, Bezbaruah BK. Antibiotic prescription patterns in pediatric department Gauhati medical college and hospital. 2011;144-8.

5. Conroy SH. Pediatric pharmacy drug therapy, MR Pharms hospital pharmacist. 2003;10(2):49-57.

6. Anke AGP, Bergner BCMW. BMJ journals-adverse drug reaction related admission in paediatrics, A prospective single centre study. 2012;1-2.

7. Posthumous AG, Bergner BCMW. Research article-Adverse drug reactionrelated admission in paediatrics, a prospective single centre study. 2012;1-2.

8. Smith RM, Gargn E, Kirkham J, Cresswell L, Smyth R, Williamson P. Research Drug article-Adverse drug reactions in children. 2012;7(3):e24061.

9. Rateef MK, Sameer E, Al-harthi, Omar I-S. Research gate- a study of adverse drug reactions in pediatric patients. 2012:261-6.

10. Cheston M, Berlin, Jr, MD. A professional version,2013;1-3.

11. Niravvachhani. Pediatric medications of Dept of pharmacology, S. J. Thakkar pharmacy college, Rajkot. 2005;15.

12. Cheston M, Berlin, Jr, MD. A professional version. 2013;1-3.

13. Milap C. Nahata and Carol takemo. Pediatrics. 2010;9-12.

14. Gracieliprado, Cristina ANTONIALI, Ronaldo celio MARIANO. Comparative study of rules employed in pediatric drug dosage calculation. 2001:116.

15. Thapalia K, Shrestha S, Bhattarai S, Basnet D, Chaudhary RK. Prescribing pattern of antibiotics in pediatric hospital in chitwan district in Nepal. 2015;4(11):131-41.

16. Manyakkulshethera, AnuradhaMaheshwari, MradulGoswami, SachdevYadav. IJPSRR 2011;10(1):88-91.

17. Pise HN, Padwal SL, Jadhav RR, Deshmukh VS, Jadhav AD, Kolhe AM. NJPPP. 2015;5(4):313-7.

18. Choudhury DK, Bezbaruah BK. Antibiotic prescription pattern in pediatric in-patient department Gauhati medical college and hospital Gauhati. 2013;3(8):144-8.

19. Kanish R, Gupta K, Shivani J, Bains HS, Sandeep K. Prescribing pattern of antibiotics in the department of pediatrics in tertiary care medical college hospital in Northern India. 2014;5(4):69-72.

20. Sharma S, Bowman C, Alladin -karanand B, Singh N. Antibiotic prescribing pattern in the pediatric emergency department at Georgetown public hospital corporation. 2016:16(1):170.

21. Gupta N, Safhi MM, Sumaily JM, Agarwal M. Drug prescribing pattern in children registered in the department of pediatrics of Jizan general hospital, Jizan. KSA. 2013;5(4):379-99.

22. Janaki R, Torbi, Dambal S. Drug prescription pattern in pediatric outpatient clinic in a tertiary hospital. 2011;15(2):77.

23. Hemamalini MB, Rekha MB, BasavarajBhandare, Adharsh E. Drug prescribing pattern among children aged less than 5 years. IJPP. 2016;3(4):182-5.

24. Akhtar MS, Vohora D, Pillai KK, Dubey K, Roy M, Najmi A, et al . Drug prescribing practices in pediatric department of a North Indian University teaching hospital. 2012;5(1):146-9.

25. Alakhali KM, Asif Ansari Shaik Mohammad. Prescribing pattern of antibiotics in pediatric patients in the Jazan region, Kingdom of Saudi Arabia. 2014;4(3):120-4.

26. Sebsibe Teni F, Shemsu Surur A, Getie A, Alemseged A, Meselu M. Medication prescribing pattern at a pediatric ward of an Ethiopian Hospital. 2014;2(4.2):23-30.

27. Gopal VD, Krishna RT, Kumar SA, Meda VS, Reddy RK. Prescribing pattern of Antibiotics in the general medicine and pediatrics department of a tertiary care teaching hospital. 2014;6(2):221-4. 